\title{
Saplings into oaks
}

At the last South Bristol GP trainers' workshop at the Saunton Sands Hotel we talked about the enormous changes in GP training and the challenges ahead with the increased time young doctors will spend in general practice. How to make use of this time was one our workshop sessions.

An article by Sibbett et al suggests:

'12 months as a GP registrar does not produce doctors with the necessary competencies and confidence to enter independent practice."

This train of thought was also echoed by an interim review of GP speciality training in the UK:

'While today's trainees are competent they are not confident in their professional and clinical abilities. ${ }^{2}$

We decided to work on this idea that GP registrars are competent but not confident. How can we help registrars to leave us not as saplings but as young oaks? In Bristol we now have speciality doctors for 18 months in general practice and if recommendation 45 of Sir John Tookes' Report on Modernising Medical Careers is carried out then we will come into line with Europe. The length of training in general practice will be extended to 5 years:

'3 years in core plus 2 years as a GP specialist registrar. ${ }^{3}$

This will mean there are new opportunities for training and particularly in the latter half of training. With exams hopefully out of the way we have a competent doctor and we could then work on confidence. As trainers we need to be able to facilitate and teach it.

When you have confidence you take it for granted but achieving it is not always straightforward and how to facilitate it is even more taxing on the philosophical mind. Confidence is that feeling of self-assurance, a freedom from doubt, and a belief in yourself and your own abilities. We may have the experience to know what to do but it is confidence that allows us to follow it through. Furthermore, confidence isn't always about being right but also about not being afraid to be wrong.

A brainstorming session came up with many ideas about how to enable confidence. The usual topics covered in training such as time management, random and problem case analysis, and NICE guidelines are all relevant and may need extra work when a 'learning need analysis' is performed. However, there were ideas which were new to some of us and worthy of application to enable confidence in a registrar. There were areas which we could add or expand in a longer training which get to the very essence of general practice.

\section{DEVELOPING CAPABILITY}

Developing capability and coping with change is vital if doctors are to survive the ravages of our political and scientific task managers. We need to enable not just competence, but also capability if our doctors are to feel confident. This was described by Fraser and Greenhalgh. ${ }^{4}$ Capability is the 'extent to which individuals can adapt to change, generate new knowledge, and continue to improve their performance.' They continue by saying that 'learning which builds capability takes place when individuals engage with uncertain and unfamiliar context in a meaningful way.' This could be uncertainty in the individual consultation or much larger change such as when the government introduces new contract requirements. Perhaps we should not behave as trainers but as peers to help learners to reflect at these times to help them understand the value of this process. This could be useful in practice if we have changes to make ourselves and share the reflection and subsequent transformation with the registrar. We work in a complex environment which requires more than just protocols to find solutions. Albert Einstein had the right idea when I believe he said:

'To raise new questions, new possibilities, to regard old problems from a new angle, requires creative imagination and marks real advance in science.'

\section{PERSONAL DEVELOPMENT}

As well as coping with change there needs to be personal development. We need to help learners to understand the everincreasing drive to demonstrate personal learning such as in the annual appraisal. We should be helping young doctors to see the value of this and not simply treat it as a chore every year. This might be achieved by teaching young doctors how to appraise others or spend time reflecting on what makes a good appraiser.

\section{MANAGING RISK AND UNCERTAINTY}

Understanding risk and uncertainty can really boost confidence. Medicine is not always predictable and having strategies to cope with unpredictability is vital. This was set out in a recent BJGP article: 'Insecurity and risk in the consultation'5 Young doctors often believe protocols will see them through and forget the importance of patient involvement in the process if they are to understand the course of illness and have realistic expectations. Having strategies such as shared safety netting makes a tremendous difference. When the patient leaves the room the doctor can feel confident that they are equipped with ideas to deal with unpredictability. Having this in place enables the use of time as a diagnostic tool which is deserving of extra attention in training.

As GPs we are seeing patients over time and do not always need to refer problems immediately. With patient agreement we can hold onto problems with the option to see patients again or use strategies such as a delayed prescription. ${ }^{6}$

\section{MANAGING PERSONAL STRESS}

The number of doctors who experience psychological distress is about $28 \%$ compared to $18 \%$ in the general population. ${ }^{7}$ Realising this and applying the helpful ideas detailed in articles such as 'How to handle stress and look after your mental health' ${ }^{18}$ would benefit registrars. In addition, using the resource 'Doctors for Doctors'9 would also be very useful for future development. 


\section{TEACHING}

Teaching is an aspect which has great value for confidence and with more time available and more learners, the experienced registrar has a lot to offer the medical student or F2 doctor. A recent registrar told one of the group that they hadn't realised how much they knew until they started to teach. One of the best ways to continue our life-long learning and affirm our knowledge and skills is to train and support learners. We make sure we are up to date, have things clear in our mind, and understand how issues fit together. No one would like to drop acorns that will never germinate!

These then are a few of the many ways we could build confidence given the opportunity of a longer training. However, perhaps the most important conclusion was for the trainers themselves to consider philosophically their role: Good trainers will ensure that the learner has confidence in the trainer, but the accomplished trainer will inspire the learner to have confidence in themselves.

\section{Jeff Clark}

\section{REFERENCES}

1. Sibbett C, Thompson WT, Crawford M, McKnight A, Learning in practice. BMJ 2003; 327: 971-973.

2. Royal College of General Practitioners. A review of GP speciality training in the UK. Interim report for the Department of Health.

http://www.rcgp.org.uk/gp training/extended_gp_speci alty_training.aspx (accessed 1 Dec 2009).

3. Tooke J. Aspiring to excellence. Final report of the independent inquiry into modernising medical careers. http://www.mmcinquiry.org.uk/MMC_FINAL_REPOR T_REVD_4jan.pdf (accessed 1 Dec 2009).

4. Fraser SW, Greenhalgh T. Coping with complexity: educating for capability. BMJ 2001; 323: 799-803.

5. Clark J. Insecurity and risk in the consultation. $\mathrm{Br} \mathrm{J} \mathrm{Gen}$ Pract 2009; 59(564): 548-549.

6. Cates C. Delayed prescriptions in primary care. $\mathrm{Br} J$ Gen Pract 2003; 53: 836-837.

7. Wall TD, Bolden RI, Borrill CS, et al. Minor psychiatric disorder in NHS trust staff: occupational and gender differences. Br J Psychiatry 1997; 171: 519-523.

8. Iverson I, Rushford B, Forrest K. How to handle stress and look after your mental health. BMJ 2009; 338 b1368.

http://www.bmj.com/cgi/content/full/338/apr27_1/b13 68 (accessed 3 Dec 2009).

9. British Medical Association. About Doctors For Doctors and BMA counselling. London: BMA, 4 Feb 2008. http://www.bma.org.uk/doctors_health/D4Dabout.jsp (accessed 1 Dec 2009).

DOI: 10.3399/bjgp10X482211

\section{ADVICE TO NEW ST1S IN GENERAL PRACTICE}

I am an ST2 trainee who has spent two 4 months blocks working in general practice (in F2 and ST1 years). I was recently asked if I had any advice to give to new GP trainees. The following list represents some tips I have picked up during my training to date that may provide some illumination and/or entertainment.

1. Never accept tea on a home visit. It will be awful and you'll be there all day.

2. Be careful about offering medical advice to receptionists, etcetera. If you're not careful you will end up running a clinic with no notes and questionable legal cover (and the partners don't like it).

3. Always do a full examination of infants and record their vital signs (including capillary refill time and respiratory rate) regardless of what they are presenting with.

4. Know how to get help urgently.

5. Know how to provide help to other GPs urgently.

6. Revise Gillick competencies.

7. Make sure you know how to refer for a termination of pregnancy, as learning on the job isn't ideal.

8. Chaperone!

9. When someone says, 'I've got a list', ask for the most serious complaint first.

10. When an older gentleman presents with mechanical back pain, make sure he has had recent bloods including PSA.

11. Learn the prescribing criteria for Viagra ${ }^{\circledR}$, men often seek out the new registrar.

12. Find out how to get in touch with the local school nurse. Also, many towns have an 'info shop' which is a great port of call for young adults who are upset/ agitated/distressed/normal.

13. Phoning the medical registrar on call can be very useful. They are much less grumpy than the SHO and know more.

14. Many hospitals have a GP-oriented website that lists local referral criteria and antibiotic guidelines.

15. Ask all doctors at your practice to let you know whenever they have any dermatology cases.

16. Buy a thermometer that measures temperature in the ear or spend time wrestling with paediatric patients. It's your choice.

17. If a patient makes you feel scared, threatened or bad about yourself then talk to someone else about them.

18. Most practices have an attached community psychiatric nurse (CPN). Get to know them.

19. When a patient tells you they are pregnant don't say congratulations until you know they are happy about it.

20. Remind oral contraceptive pill users to take extra precautions when prescribing them antibiotics.

21. If the practice nurse asks you to review one of their patients, then review the patient.

22. Take in cake on your first and last day.

23. Find out the practice telephone number that bypasses the recorded stuff and gets you through to a receptionist straight away.

24. Get your supervisor's mobile number.

25 . When your Friday afternoon list is overrunning and going pear-shaped, remind yourself that you are not working on Saturday.

26. Go to the beach.

27. Get to know the local residential/nursing/ EMI homes. It will come in handy.

28. Have a laugh. It's a long day without one.

29. Learn to say 'no'

30 . Find out the local 2-week rule criteria.

31. Know how to spot a malignant melanoma.

32. Anyone who feels they are poorly enough for a home visit should have vital signs recorded.

33. Learn to ride a motorcycle.

34. Don't ignore child protection concerns but do get help.

35. Never skip lunch.

36. Hit the ePortfolio hard in GP placements, you are seeing a lot and are sat at a computer. It's much harder in hospital jobs.

37. Book holiday early. Book holiday for your next job now.

38. The Oxford Handbook of General Practice is worth owning.

39. Find out how to get an urgent ECG done at your practice.

40. Beware the patient you don't like, they sometimes really do have something wrong with them!

\section{Matthew Burkes}

DOI: 10.3399/bjgp10X482220 